Fourth International Conference on Sustainable Construction Materials and Technologies http://www.claisse.info/Proceedings.htm

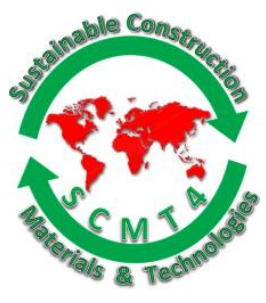

SCMT4

Las Vegas, USA, August 7-11, 2016

\title{
Optimal Composition of Blended Waste Ceramic Aggregate
}

\author{
Jacek Katzer ${ }^{1 a}$, and Elżbieta Kuźmińska ${ }^{1 b}$ \\ ${ }^{1}$ Faculty of Civil Engineering Environmental and Geodetic Sciences, \\ Koszalin University of Tech-nology, POLAND. \\ ${ }^{1 a}$ Email: <jacek.katzer@tu.koszalin.pl>, ${ }^{1 b}$ Email: <elzbieta.kuzminska@tu.koszalin.pl>.
}

\begin{abstract}
The research programme focused on two types of waste aggregate was conducted. There were prepared mortars based on specifically composed aggregates (blend of natural sand, red waste ceramic aggregate and white waste ceramic aggregate). There was utilized simplex experiment design. Alltogether, 10 blends of aggregates were prepared. The grading characteristics of all the aggregates' blends was constant. All aggregates were thoroughly tested before casting mortars. Such propertes of hardened mortars as density, flexural and compressive strength were of special interest.
\end{abstract}

\section{INTRODUCTION}

Worldwide, there is a growing research effort to successfully harness different ceramic wastes in construction industry. So far it has resulted in successful applications of red ceramic waste in concrete elements characterized by less demanding mechanical characteristics [de Brito et al. 2005, Łapko \& Grygo 2014]. In order to utilize waste ceramic aggregate for production of structural concrete a new approach to its composition is needed. In authors' opinion different waste ceramic aggregates should be blended together (e.g. red waste ceramic aggregate - RWCA and white waste ceramic aggregate - WWCA) to achieve new quality in sustainable concrete production. Red ceramic due to its porosity is characterized by limited compressive strength but gives the advantage of internal curing process [Bentur et al. 2001, Suzuki 2009] in contrary to the white one, which is characterized by "no porosity" and much

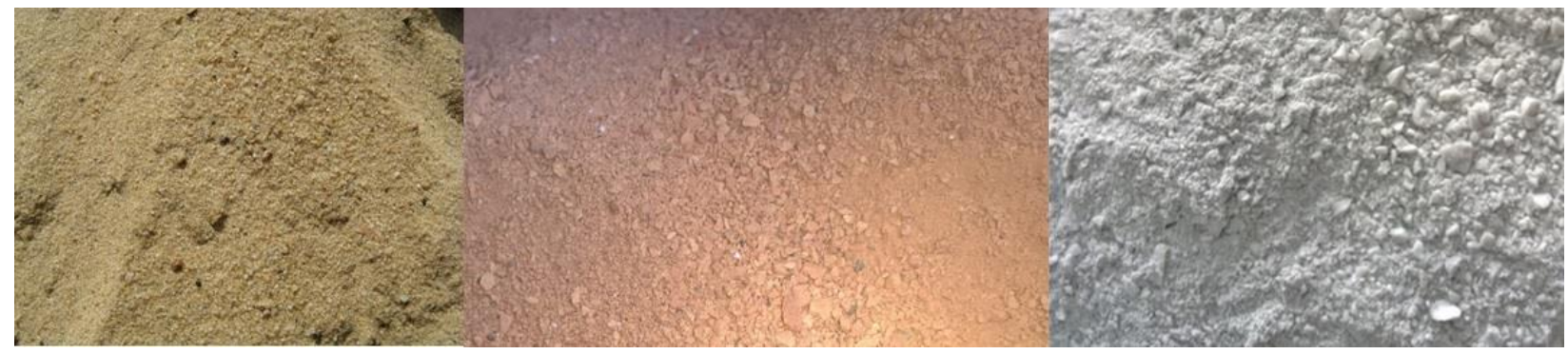

Figure 1. Used Natural Sand, RWCA and WWCA 
higher compressive strength. The research programme was based on RWCA (obtained from debris of construction origin) and WWCA (obtained from chinaware production waste). Both aggregates were prepared using the same machinery and grinding procedure. As a reference the properties of natural postglacial sand commonly available along southern shoreline of the Baltic Sea [Katzer \& Kobaka 2006] was chosen. The research programme was divided into two stages. The first stage covered testing geometrical and mechanical properties of the waste aggregates and natural sand. All three aggregates are presented in figure 1. The second stage covered the tests of properties of mortars made on the basis of waste aggregates and natural aggregate tested during the first stage. The analysis of possible replacement of natural aggregate by waste ceramic aggregates was conducted. Specific mixtures of both waste ceramic aggregates and natural aggregate were proposed to harness in concrete production.

\section{EXPERIMENTAL INVESTIGATION}

Materials. The aggregates were specially prepared for the research programme. Grading of all three aggregates was the same. They were sieved into separate fractions and then composed to mirror the grading characteristics of sand used for cement testing as described in European [EN 196-1] and American [ASTM C305] standards. All three composed aggregates were characterized by median diameter $d_{m}$ [Katzer 2012] equal to $0.77 \mathrm{~mm}$. The aggregates were thorougly tested according to

[EN 933-1;

EN 1097-1,-3,-6; EN 1367-1]. Such properties as density, absorbability, freezing-thowing resistance and abrasion resistance were of special interest. The Los Angeles abrasion test was harnessed as a most common test method used to indicate aggregate toughness and abrasion characteristics. Achived results are presented in Table 1.

Table 1. Properties of Natural Sand, RWCA and WWCA

\begin{tabular}{|l|c|c|c|}
\hline \multicolumn{1}{|c|}{ Property } & Natural Sand & RWCA & WWCA \\
\hline Density $\left[\mathrm{g} / \mathrm{cm}^{3}\right]$ & 2.650 & 1.690 & 2.400 \\
\hline Loose bulk density $\left[\mathrm{g} / \mathrm{cm}^{3}\right]$ & 1.569 & 1.007 & 1.243 \\
\hline Compacted bulk density $\left[\mathrm{g} / \mathrm{cm}^{3}\right]$ & 1.783 & 1.381 & 1.541 \\
\hline Absorbability [\%] & - & 16.8 & 0.0 \\
\hline Threez-thow ressistance [\%] of mass loss & 0.06 & 0.17 & 0.01 \\
\hline Abrasion ressiatance [\%] of L.A. mass loss & 24 & 44 & 24.5 \\
\hline
\end{tabular}

To prepare the mortars there was used Portland Cement CEM I 42.5 N-NA [EN 197-1:2000] and tap water [EN 1008:2002]. The standard mortar mix used for tests of cement compressive strength [EN 196-1] was utilized as a base mix $(\mathrm{w} / \mathrm{c}=0.5, \mathrm{a} / \mathrm{c}=3.0)$.

Experiment design. The three aggregates were coded as follows: $X_{1}$ - natural sand; $X_{2}-$ RWCA; $X_{3}$ WWCA. Due to different specific gravity of red ceramic, white ceramic and natural sand all aggregate were dosed by volume. There was utilised an integral simplex design also known as 'a mixture design' [Bayramov et al. 2004]. The sum of volume of all three aggregates was always equal to $100 \%$. This design was described in detail in Table 2 and spacing of measuring points was shown in figure 2 . The object of the experiment was considered as a complex material whose structure is unknown and unavailable for an observer, but the 'input' and 'output' parameters are known [Mann 1950, Schenk 1979]. The examination results were statistically processed. Values bearing the gross error were assessed on the basis of SmirnowGrabbs criterion. The objectivity of the conducted experiments was assured by using a table of random numbers to choose the sequence of the realization of specific experiments. All calculations associated with specifying and graphic interpretation of the received mathematic model were carried out with the help of Statistica 10.0 computer programme. Contour plots were achieved by using polynomial fit. Fitted functions 
are characterized by correlation coefficient equal to at least 0.80 . This type of experiment design was successfully used numerous times in technology of concrete [Bayramov et al. 2004].

Table 2. Experiment design

\begin{tabular}{|c|c|c|c|c|c|c|c|}
\hline $\begin{array}{c}\text { Composite } \\
\text { number }\end{array}$ & $\begin{array}{c}\text { Reali- } \\
\text { zation } \\
\text { sequence }\end{array}$ & $X_{1}$ & $X_{2}$ & $X_{3}$ & $\begin{array}{c}\text { Natural } \\
\text { Sand } \\
{[\mathrm{g}]}\end{array}$ & $\begin{array}{c}\text { RWCA } \\
{[\mathrm{g}]}\end{array}$ & $\begin{array}{c}\text { WWCA } \\
{[\mathrm{g}]}\end{array}$ \\
\hline C1 & 7 & 1.000 & 0.000 & 0.000 & 1325 & 0 & 0 \\
\hline C2 & 4 & 0.000 & 1.000 & 0.000 & 0 & 900 & 0 \\
\hline C3 & 9 & 0.000 & 0.000 & 1.000 & 0 & 0 & 1170 \\
\hline C4 & 2 & 0.667 & 0.333 & 0.000 & 883 & 300 & 0 \\
\hline C5 & 10 & 0.333 & 0.667 & 0.000 & 442 & 600 & 0 \\
\hline C6 & 6 & 0.000 & 0.667 & 0.333 & 0 & 600 & 390 \\
\hline C7 & 1 & 0.000 & 0.333 & 0.667 & 0 & 300 & 780 \\
\hline C8 & 8 & 0.333 & 0.000 & 0.667 & 442 & 0 & 780 \\
\hline C9 & 3 & 0.667 & 0.000 & 0.333 & 883 & 0 & 390 \\
\hline C10 & 5 & 0.333 & 0.333 & 0.333 & 442 & 300 & 390 \\
\hline
\end{tabular}

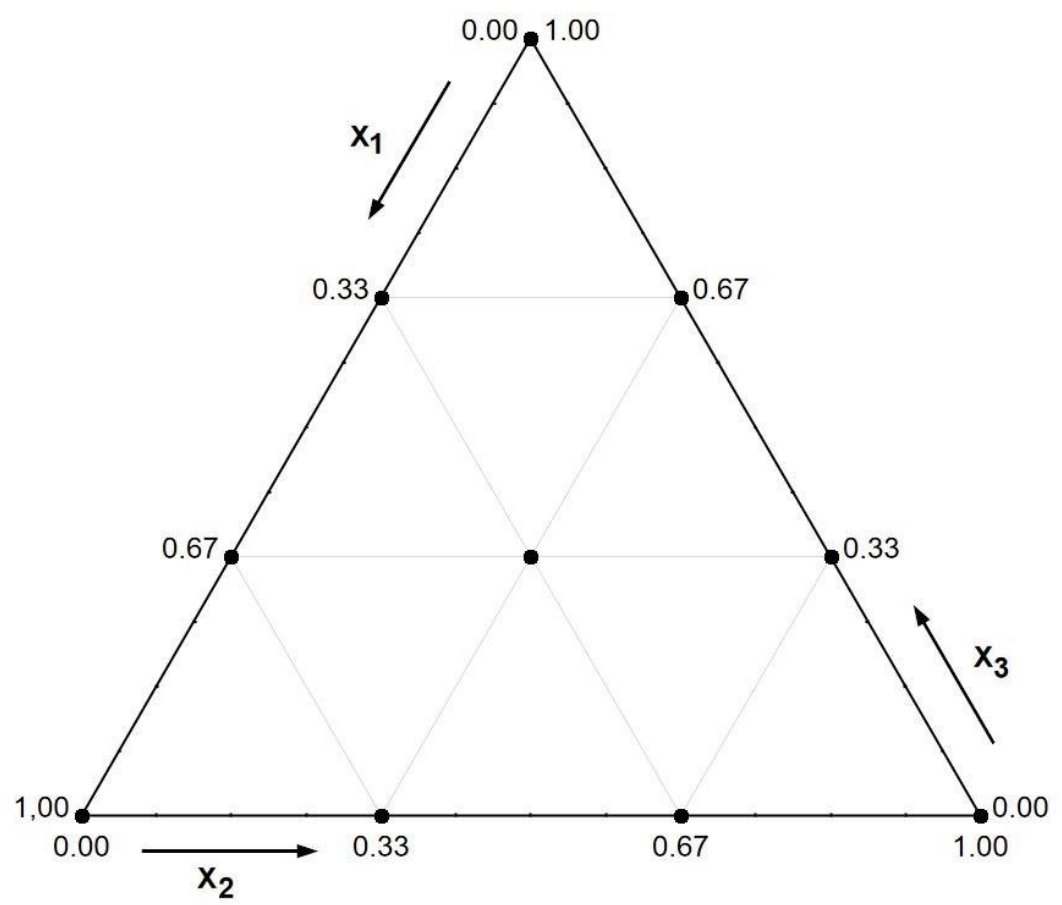

Figure 2. Design of experiment - spacing of testing points 
Specimens and testing procedure. The specimens were in a form of beams $16 \mathrm{~cm} \cdot 4 \mathrm{~cm} \cdot 4 \mathrm{~cm}$. For the first $24 \mathrm{~h}$ the specimens were kept in their moulds covered with glass plates. The specimens were then removed from their moulds and cured in a water tank (temp.: $\left.+21{ }^{\circ} \mathrm{C}\right)$. The specimens were tested after 28 days of curing. The beams were firstly subjected to flexural strength test (two supports $-10 \mathrm{~cm}$ span, one loading point in the middle of the span). Two halves of a beam were then subjected to the compressive strength test. The compression area was equal to $16 \mathrm{~cm}^{2}$. The tests were conducted in compliance with European Standard [EN 196-1]. There were cast 16 beams of each mix. Therefore, for each tested composite there was a population of 16 results of flexural strength and 32 results of compressive strength.

\section{RESULTS AND DISCUSSION}

Density of hardened compositess was the first tested property. It was ranging from values below 1.995 $\mathrm{kg} / \mathrm{dm}^{3}$ for composite based sololy on RWCA to values over $2.312 \mathrm{~kg} / \mathrm{dm}^{3}$ for composite based sololy on natural sand. Composite created using only WWCA was characterized by density of $2.097 \mathrm{~kg} / \mathrm{dm}^{3}$. The full results are presented in figure 3 .

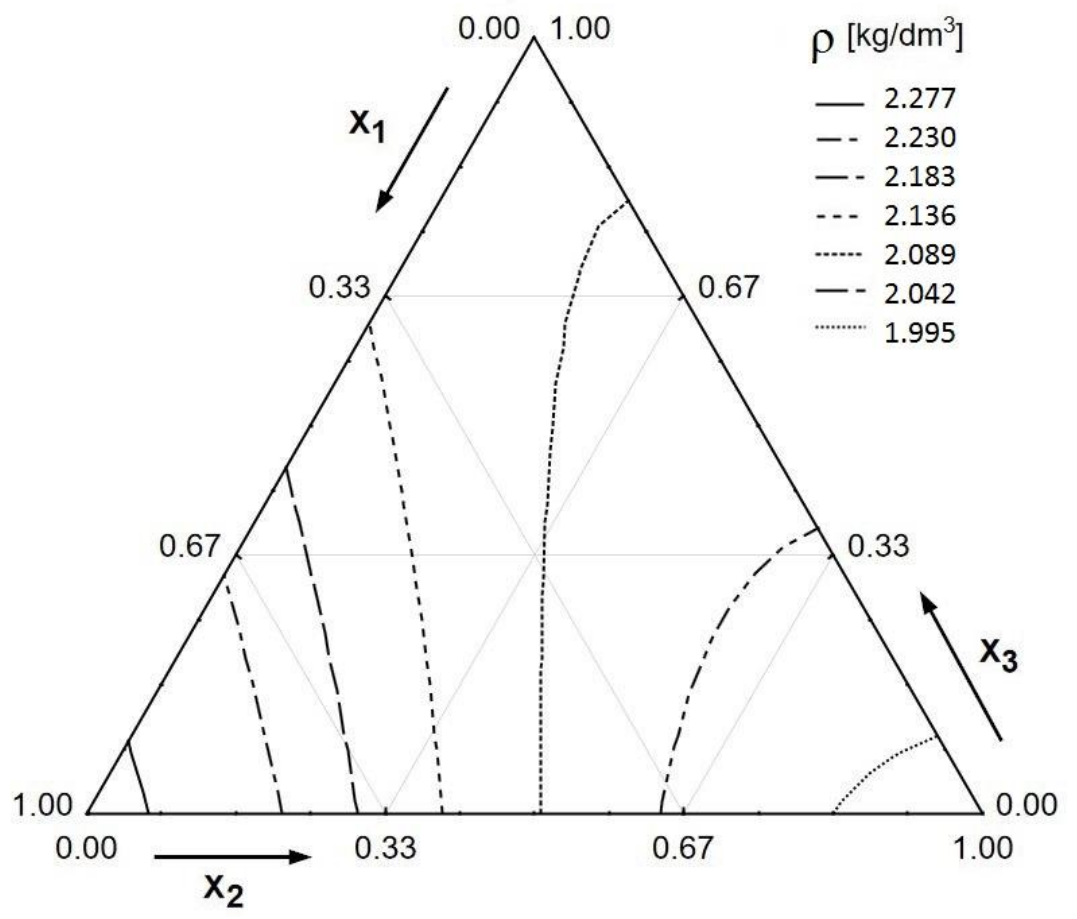

Figure 3. Density of tested mortars

The results of flexural strength test are presented in figure 4. Composite C6 (67\% of RWCA and 33\% of WWCA) was characterized by the highest flexural strength of 8.1 MPa. The lowest flexural strength of 7.0 $\mathrm{MPa}$ was achived by composite $\mathrm{C} 1$ which was created usiung only natural sand. Composites based sololy on RWCA (C2) and WWCA (C3) were characterized by flexural strength of $7.7 \mathrm{MPa}$ and $7.4 \mathrm{MPa}$ respectively. The difference in flexural strength between composite $\mathrm{C} 1$ and $\mathrm{C} 6$ is equal to $15.7 \%$. This increase was probabely caused by rough surface of both waste aggregates. It enables better bonding with cement matrix and thus influences the flexural strength. 


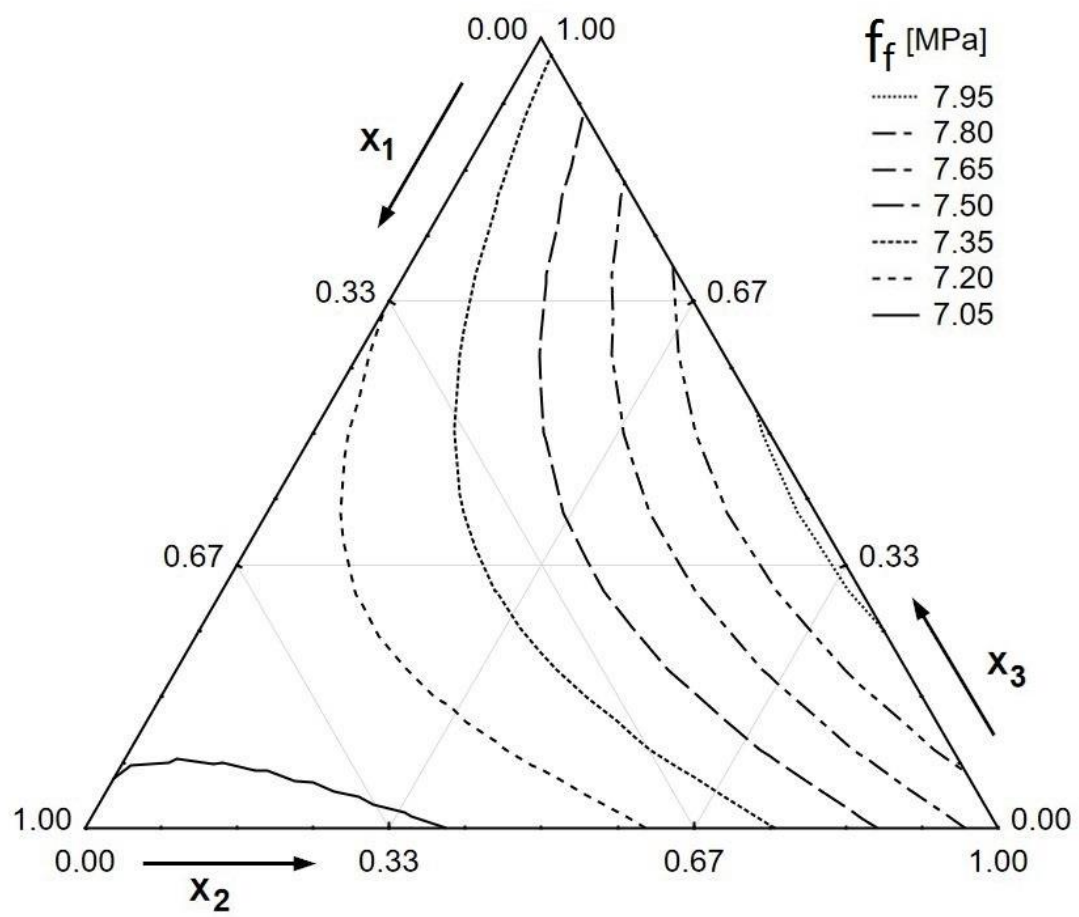

Figure 4. Flexural strength of tested mortars

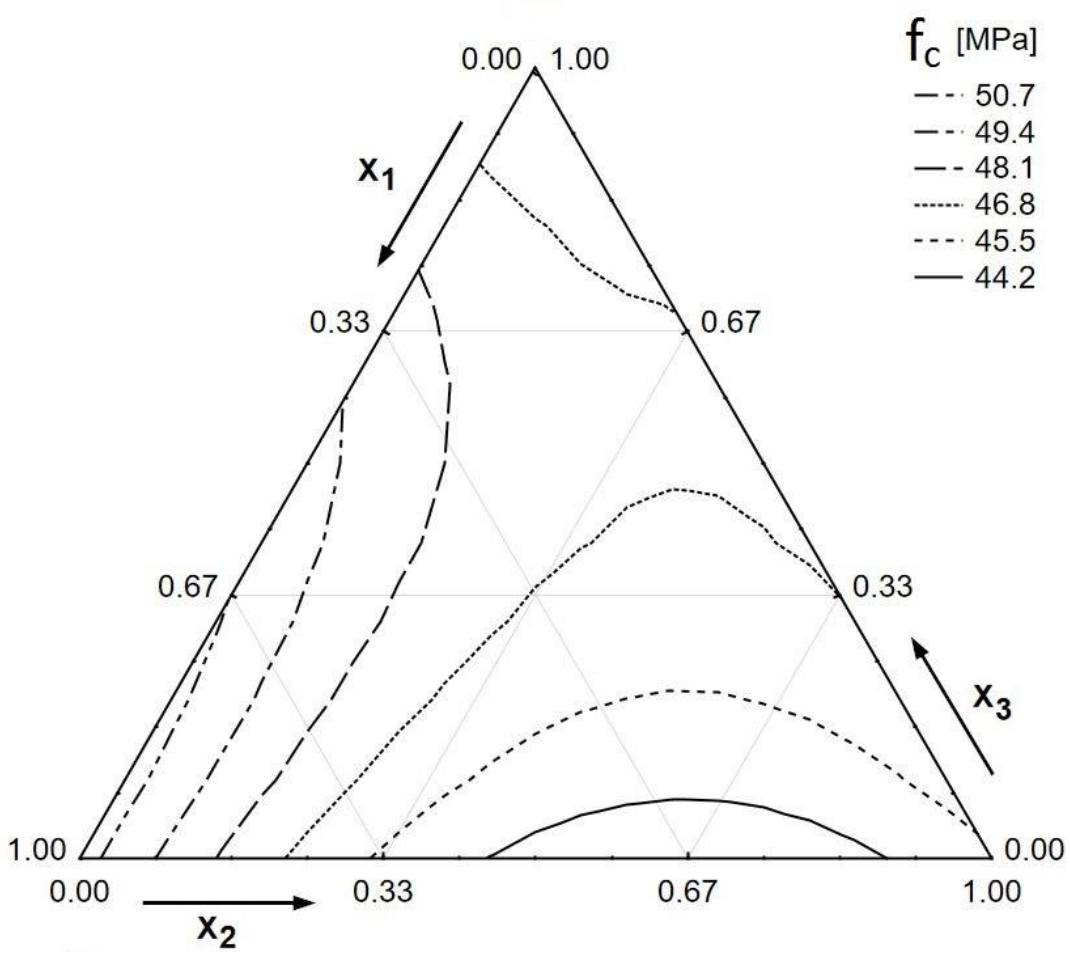

Figure 5. Compressive strength of tested mortars 
The lowest compressive strength of $43.1 \mathrm{MPa}$ was achived by composite C5 (67\% of RWCA and 33\% of natural sand).Composites based sololy on RWCA and WWCA were characterized by similar compressive strength of 45.0 MPA and 45.8 MPa respectively. Composite $\mathrm{C} 1$ created using only natural sand was characterized by the highest compressive strength eqaul to $51.4 \mathrm{MPa}$. The difference between the weakest and strongest composites was equal to $16.1 \%$. Keeping in mind fine grading characteristcs of the aggregates the created composites are a perfect matrix for fibre reinforcment [Domski 2015].

\section{CONCLUSION}

The following conclusions can be drawn from the research programme described in the paper:

- It is possible to cast composites based on multiple waste aggregates

- A blend of waste ceramic aggregates allow to achive the flexural strength of a cement composite higher then in case of ordinary natural sand

- The highest compressive strength can be achived using only natural aggregates

- It is possible to substitute natural aggregate by WRCA and WWCA

- The composites created on the basis of WRCA and WWCA are characterized by plausible mechanical properties

- The research programme should be continued using bigger specimens. It should be focused on more complicated mechanical characteristics (e.g. dynamic properties) of composites in question to full scale allow modelling

\section{REFERENCES}

ASTM C305 - 14. "Standard Practice for Mechanical Mixing of Hydraulic Cement Pastes and Mortars of Plastic Consistency", ASTM International.

Bayramov F., et al. "Optimalisation of steel fibre reinforced concretes by means of statistical response surface method." Cem Concr Compos, 2004; 26(4):665-75.

Bentur A., Igarashi S., Kovler K. "Prevention of autogenous shrinkage in high strength concrete by internal curing using wet lightweight aggregates." Cem Concr Res 2001; 31(11): 1587-91.

de Brito J., Pereira A.S., Correia J.R. "Mechanical behaviour of non-structural concrete made with recycled ceramic aggregates." Cem Concr Compos 2005; 27(4):429-33.

Domski J. "Long-term study on fibre reinforced fine aggregate concrete beams based on waste sand." Rocznik Ochrona Środowiska (Annual Set the Environment Protection) 2015, vol. 17, 188-199.

EN 196-1. "Methods of testing cement - Part 1: Determination of strength", European Standards.

EN 197-1:2000. Cement. "Composition, specifications and conformity criteria for common cements", European Standards.

EN 933-1 "Tests for geometrical properties of aggregates -Part 1: Determination of particle size distribution - Sieving method", European Standards.

EN 1008:2002. "Mixing water for concrete. Specification for sampling, testing and assessing the suitability of water, including water recovered from processes in the concrete industry, as mixing water for concrete", European Standards.

EN 1097-2. "Tests for mechanical and physical properties of aggregates - Part 2: Methods for the determination of resistance to fragmentation", European Standards. 
EN 1097-3. "Tests for mechanical and physical properties of aggregates - Part 3: Determination of loose bulk density and voids", European Standards.

EN 1097-6 "Tests for mechanical and physical properties of aggregates - Part 6: Determination of the particle density and water absorption", European Standards.

EN 1367-1 "Tests for thermal and weathering properties of aggregates - Part 1: Determination of resistance to freezing and thawing", European Standards.

Katzer J. "Median diameter as a grading characteristic for fine aggregate cement composite designing." Construction and Building Materials 2012, vol. 35, issue 11, 884-887.

Katzer J., Kobaka J. "The assessment of fine aggregate pit deposits for concrete production.” Kuwait Journal of Science and Engineering, Vol. 33, Issue 2/2006, 165-174.

Łapko A., Grygo R. "Effectiveness of the use of recycling aggregate concrete for sustainable building structures.” Rocznik Ochrona Środowiska (Annual Set the Environment Protection) 2014, vol. 16, 627638.

Mann H. B. “Analysis and design of experiments.” New York, (USA): Dover Publications; 1950.

Schenk H. "Theories of engineering experimentation.” USA: Hemisphere Publishing Co.; 1979.

Suzuki, M., et al., (2009). "Use of porous ceramic waste aggregates for internal curing of high-performance concrete." Cement and Concrete Research, 39, 373-381. 